\title{
Open conversion in laparoscopic cholecystectomy and bile duct exploration: subspecialisation safely reduces the conversion rates
}

\author{
Ahmad H. M. Nassar ${ }^{1,4}$ (D) Hisham El Zanati ${ }^{2,4} \cdot$ Hwei J. Ng $^{3,4} \cdot$ Khurram S. Khan $^{3,4} \cdot$ Colin Wood ${ }^{3,4}$
}

Received: 13 August 2020 / Accepted: 9 January 2021 / Published online: 2 February 2021

(c) Crown 2021

\begin{abstract}
Background Open conversion rates during laparoscopic cholecystectomy vary depending on many factors. Surgeon experience and operative difficulty influence the decision to convert on the grounds of patient safety but occasionally due to technical factors. We aim to evaluate the difficulties leading to conversion, the strategies used to minimise this event and how subspecialisation influenced conversion rates over time.

Methods Prospectively collected data from 5738 laparoscopic cholecystectomies performed by a single surgeon over 28 years was analysed. Routine intraoperative cholangiography and common bile duct exploration when indicated are utilised. Patients undergoing conversion, fundus first dissection or subtotal cholecystectomy were identified and the causes and outcomes compared to those in the literature.

Results 28 patients underwent conversion to open cholecystectomy ( $0.49 \%)$. Morbidity was relatively high (33\%). 16 of the 28 patients $(57 \%)$ had undergone bile duct exploration. The most common causes of conversion in our series were dense adhesions $(9 / 28,32 \%)$ and impacted bile duct stones (7/28, 25\%). 173 patients underwent fundus first cholecystectomy (FFC) (3\%) and 6 subtotal cholecystectomy (0.1\%). Morbidity was $17.3 \%$ for the FFC and no complications were encountered in the subtotal cholecystectomy patients. These salvage techniques have reduced our conversion rate from a potential $3.5 \%$ to $0.49 \%$. Conclusion Although open conversion should not be seen as a failure, it carries a high morbidity and should only be performed when other strategies have failed. Subspecialisation and a high emergency case volume together with FFC and subtotal cholecystectomy as salvage strategies can reduce conversion and its morbidity in difficult cholecystectomies.
\end{abstract}

Keywords Laparoscopic cholecystectomy $\cdot$ Conversion $\cdot$ Difficult cholecystectomy $\cdot$ Nassar scale $\cdot$ Fundus first cholecystectomy $\cdot$ Subtotal cholecystectomy

After the first laparoscopic cholecystectomy was performed by Mühe in Germany in 1986, the procedure became one of the most common surgical procedures performed worldwide [1].

Ahmad H. M. Nassar

ahmad.nassar@glasgow.ac.uk; anassar@doctors.org.uk

1 Department of Surgery, University Hospital Monklands, Airdrie, Lanarkshire, UK

2 Department of Surgery, University Hospital Hairmyres, East Kilbride, Lanarkshire, UK

3 Department of Surgery, NHS Greater Glasgow and Clyde, Glasgow, UK

4 Laparoscopic Biliary Service, University Hospital Monklands, Monkscourt Avenue, Airdrie, Lanarkshire, Scotland ML6 0JS, UK
Conversion from laparoscopic cholecystectomy (LC) to open cholecystectomy (OC) may be resorted to for various reasons with reported rates of $1 \%$ to $15 \%[2,3]$. Open conversion increases the operative time, complication rates, perioperative costs and the length of hospital stay [4-6].

Difficult cholecystectomies are usually associated with severe inflammation that distorts the anatomy and renders dissection more difficult (i.e. acute cholecystitis, empyema, gangrene, perforation and Mirizzi syndrome) or with liver cirrhosis increasing the risk of bleeding and a higher probability of conversion. As laparoscopic skills increase surgeons become more able to utilise different techniques to reduce their conversion rates. Some strategies were already well established in OC such as fundus first dissection (FFD) and subtotal cholecystectomy [7].

Acute cholecystitis was once considered a contraindication to LC [8]. However, the current guidelines of several 
international societies suggest that these patients should be offered an early LC [9]. Surgeons are thus likely to be exposed to more difficult gall bladders with the potential for an increase in open conversion.

\section{Methods}

Prospectively collected data from 5738 LC performed by a single surgeon (AHMN) or his trainees under direct on-table supervision over 28 years were reviewed. Data on patient demographics, type of admission, clinical presentation, radiological findings, interval from admission to surgery, operative difficulty grade, operative time, perioperative complications, re-admissions and mortality were recorded.

Cases that underwent conversion to open cholecystectomy were identified and their preoperative, operative and postoperative data were analysed.

This biliary firm managed, by protocol, most referrals of biliary emergencies within the hospital and occasionally inter-hospital transfers. A minimum emergency workload of $60 \%$ is agreed according to the consultant's job plan. The unit adopts a policy of intention to treat during the index emergency admission and single session laparoscopic management of bile duct stones.

We do not routinely rely on preoperative MRCP or ERCP to investigate or treat patients with suspected bile duct stones. However, cross-sectional imaging is carried out when any patients presenting with jaundice have any risk factors to suspect malignancy. We perform routine intraoperative cholangiography (IOC) and, when indicated, laparoscopic bile duct exploration (LCBDE). IOC helps clarify the anatomy of the biliary tree particularly in difficult cases. We use the Nassar difficulty grading scale to document operative difficulty of the cholecystectomy. This has been shown to standardise the description of operative findings by different surgeons in order to facilitate audit, training assessment and research. It provides a tool for reporting disease severity and technical difficulty and can be utilised to reliably compare outcomes according to case mix and operative complexity [10].

\section{Operative technique and strategies for difficult LC}

A four port technique is employed in the American position. Modified open access is established through an infraumbilical 11-12 $\mathrm{mm}$ port and three $5 \mathrm{~mm}$ epigastric, sub-costal and right flank ports. The first access port should be inserted at a different point to avoid abdominal scars, usually at the epigastrium. Adhesions between the gallbladder and omentum or bowel loops were divided using sharp or blunt dissection. Bowel adhesions are divided at the interface with parietal peritoneum, or with the gallbladder or liver. Adhesiolysis is limited to the minimum needed to clear the port sites and sweep bowels away from the operating field and subsequently camera ports do not need to follow the classical distribution (Fig. 1). The cystic pedicle is dissected using a blunt "duckbill dissector" (Karl Storz, Tutlingen, Germany). The diathermy hook was abandoned after the first few cases and has no place in our practice. As most

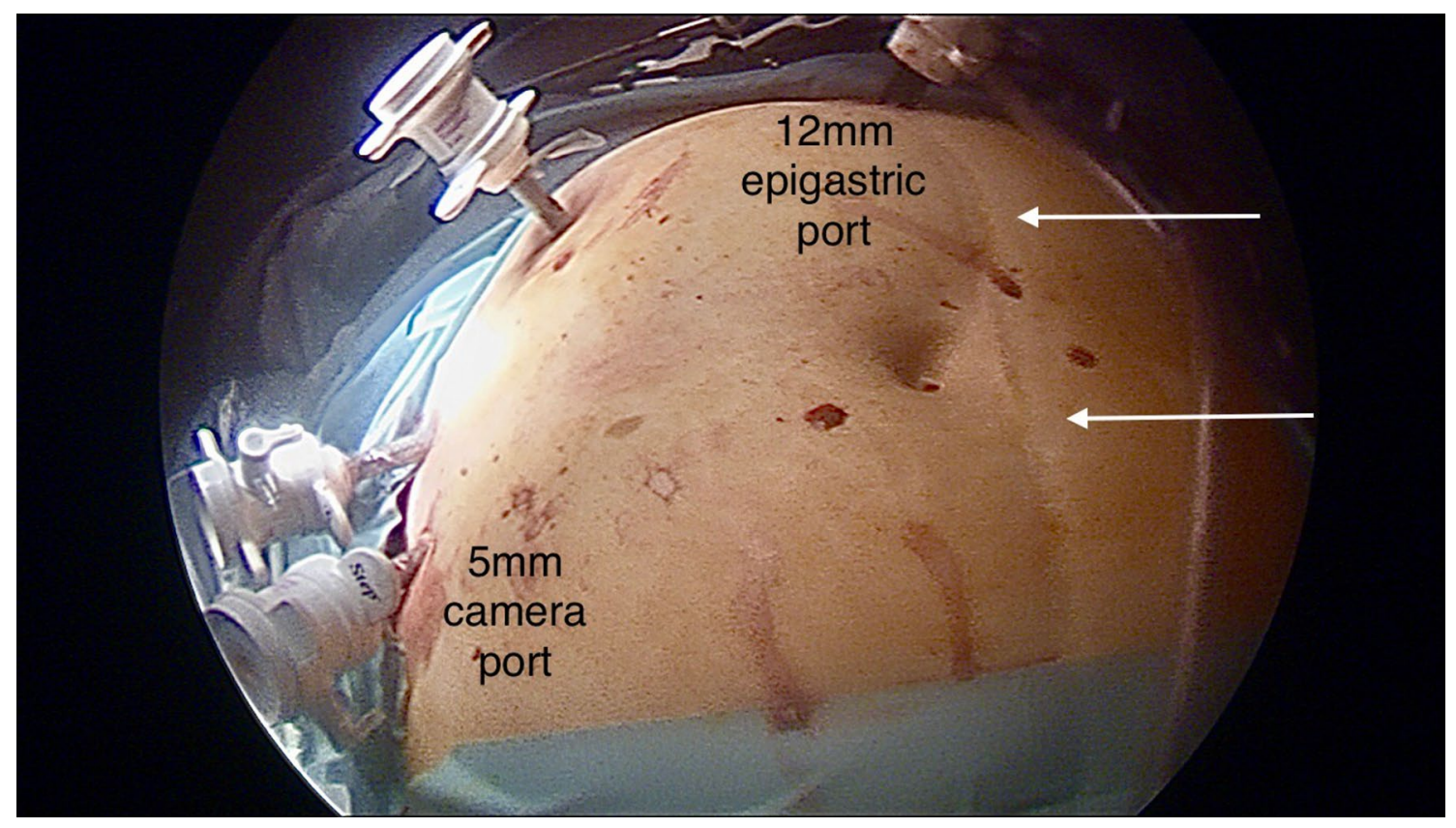

Fig. 1 Modified epigastric access avoiding a midline scar and adhesions in the centre of the abdomen using a lateral camera port 
conversions occurred in the early part of the series, dissection of the Calot's triangle employed the infundibular view approach. A policy of routinely seeking to display the critical view of safety (CVS) was adopted in the last 5 years.

Once the gallbladder/cystic duct junction and the cystic artery were identified and isolated and the CVS obtained, the neck of the gallbladder was ligated using 2-0 absorbable suture. The cystic duct was incised close to the gallbladder neck, a cholangiography catheter (Cook Medical INC, USA) was inserted into a cholangiography cannula (Karl Storz, Tutlingen, Germany) through the right sub-costal port and operative cholangiography was obtained [11]. Once the anatomy of the main bile ducts was clarified and CBD stones were excluded, the cystic duct was ligated using absorbable 2-0 suture material and divided. The use of metal clips to secure the cystic duct was abandoned 23 years ago. Gallbladder separation was then carried out using the "duckbill dissector", opening windows in the peritoneal reflection, the jaws creating a sub-serosal plane and sweeping the gallbladder away from the liver.

When a difficult cholecystectomy is encountered, the difficulty grade is determined soon after trial dissection and a first time-out is used to decide on which techniques are used to facilitate further dissection, aiming at safely avoiding conversion. A tense or thick-walled gallbladder (acute cholecystitis (AC), empyema, mucocele) is decompressed. Grasping the gallbladder may occasionally be facilitated by making a small incision at the fundus to insert one of the grasper's jaws. A packed gallbladder may be opened and evacuated. Hartmann's Pouch stones (HPS) were either pushed back into the gallbladder or occasionally removed to facilitate the dissection of the cystic pedicle or cystic plate. An effort is made to identify the cystic lymph node as a marker of the underlying cystic artery. A sub-serosal approach at the Hartman's pouch or the body of the gallbladder facilitates dissection close to the wall of an inflamed thick-walled gallbladder [12]. When a contracted gallbladder is encountered, dissection around the body of the gallbladder or FFD is considered. FFD stops short of the area of the right hepatic artery/duct and transvesical IOC through the body or infundibulum of the gallbladder is performed, especially if a Mirizzi Syndrome abnormality was suspected [13]. If IOC could not be obtained, the gallbladder body is divided horizontally creating a "funnel-shaped remnant" presenting the whole contour of the Hartman's pouch and allowing safe blunt posterior dissection (Fig. 2A and B). In our practice, this helps to achieve a complete laparoscopic cholecystectomy, reducing the incidence of subtotal cholecystectomy (SC) which was rarely resorted to in this series.

Informed consent was obtained from all patients with specific emphasis on the specialisation of the unit with regard to the management of suspected bile duct stones. IRB approval was not required as the management protocols were in line with the recommendations of national and international societies. Statistical analysis: Qualitative data were given as frequency and percentages. The $p$ values and odds ratio with $95 \%$ confidence interval for categorical values were calculated using two-tailed Fishe's exact test. $p$ values $<0.05$ were considered statistically significant.

\section{Results}

28/5738 patients underwent conversion to open cholecystectomy $(0.49 \%)$. Most of the conversions occurred in the earlier part of our series as shown in Fig. 3. This shows the effect of the learning curve and the case load on the development of experience, subspecialisation and increased skill in dealing with complex cases. Half the conversions in this series occurred in the first four years $(8 / 261$ cholecystectomies and $6 / 24$ bile duct explorations). 10 of the converted patients $(37 \%)$ were males (a conversion rate for male patients in the series of $0.7 \%$ ) and 18 were females (conversion rate of $0.4 \%$ ). Age ranged from 26 to 78 years with a mean age of 55 years. The conversion rate for male patients 60 years of age or over was $0.76 \%$.

9 of the procedures (32\%) were elective admissions and 19 were emergencies (68\%). The median admission to surgery interval in the emergency admissions was 3 days (range 1-10 days). 7 patients were referred following investigations by other surgeons or from other hospitals, resulting in 3 of the longest referral to surgery intervals.

5 patients had previous abdominal surgery (17.9\%) and 6 had documented previous episodes of cholecystitis (21.4\%). The conversion rates relative to specific traditional risk factors are shown in Table 1 . The only significant predictors of conversion in this cohort were emergency admission, presenting with jaundice, a history of previous acute cholecystitis and a dilated CBD on ultrasound scan. 14 patients in this cohort presented with jaundice. Only one had undergone an ERCP and CT reported as showing CBD stones but was found at surgery to have an empyema of the gallbladder and a cholangiocarcinoma requiring a hepaticojejunostomy. None of these 14 jaundiced patients had an MRCP as 12 were treated in the early part of the series before MRCP became available and the last two were young patients with no risk factors for cancer.

Of the 680 patients found at operation to have acute cholecystitis or empyema of the gallbladder, 6 were converted $(0.8 \%)$. However, two of these conversions were due to a suspicion of malignancy and one was due to an impacted stone in a Mirizzi Type 1 case. Only three were caused by the condition of the gall bladder, a conversion rate similar to the rest of the series. In the whole series, 16 patients who underwent laparoscopic bile duct explorations had undergone previous biliary interventions: 9 
Fig. 2 A A contracted gallbladder with a sessile junction with the common bile duct may make it impossible to display the critical view of safety. B FFD culminating in the "funnel method' facilitating safer and further posterior dissection to achieve a complete cholecystectomy
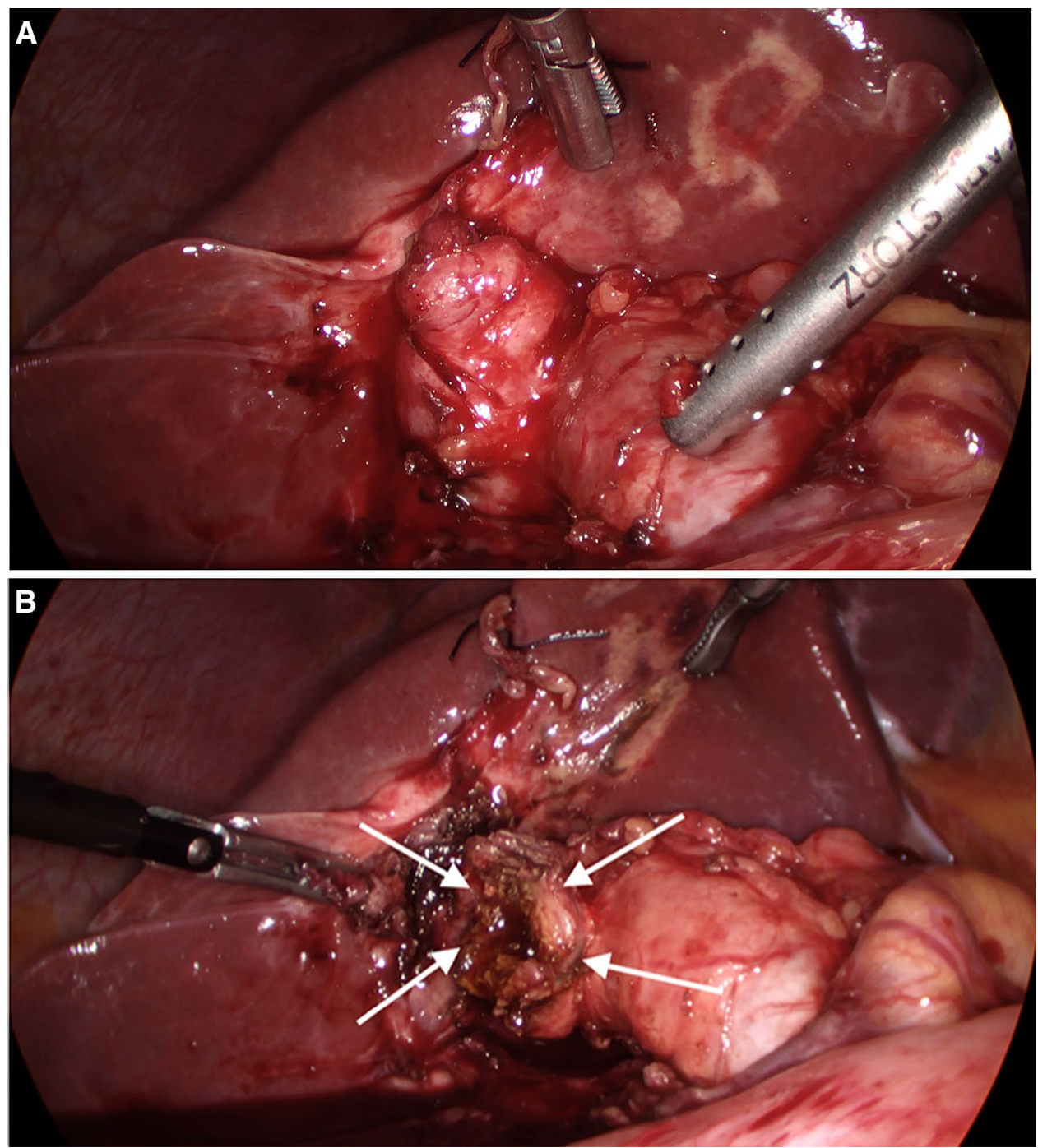

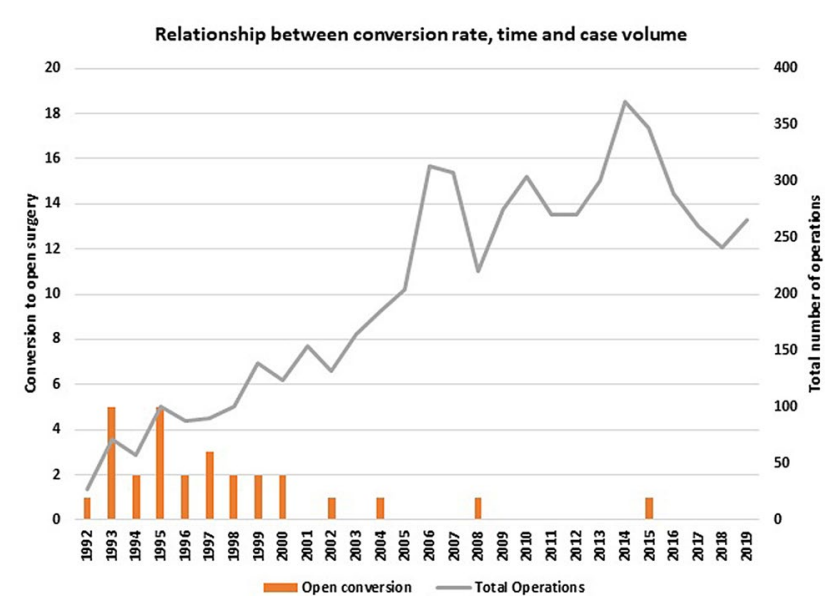

Fig. 3 Relationship between conversion rate, time and case volume

open cholecystectomies and 7 laparoscopic cholecystectomies. 4 patients who had previous cholecystectomies were subsequently optimised and had laparoscopic cholecystectomies (patients who remained unfit for surgery are not part of the study). None of the patients with previous biliary procedures required open conversion.

16 conversions (57\%) occurred in patients who underwent 1318 CBD exploration, a 1.2\% conversion rate. The most common causes of conversion in our series were dense adhesions in 9 patients (32\%), impacted CBD stones in 7 (25\%), 3 of which could not be removed at open surgery and required a choledochoduodenostomy and Mirizzi syndrome in 4 cases.

The causes of conversion in this series are shown in Table 2. At operation, adhesions between the gallbladder and the hepatic flexure were reported in 18 patients and between the gallbladder and the duodenum in 11 and to both viscera in 9 . The cystic pedicle area was reported as difficult in 23 cases with 20 patients $(71.5 \%)$ being difficulty grade 4 or 5.6 of the 173 patients subject to FFD had open cholecystectomy. However, all of the last $135 \mathrm{FF}$ 
Table 1 Conversion rates relative to specific preoperative risk factors

\begin{tabular}{|c|c|c|c|c|c|c|}
\hline Preoperative risk factors & $\begin{array}{l}\text { Risk factor } \\
\text { positive no }\end{array}$ & Conversion no (\%) & $\begin{array}{l}\text { Risk factor } \\
\text { negative no }\end{array}$ & Conversion nso (\%) & $p$ value & OR $(95 \% \mathrm{CI})$ \\
\hline Age $\geq 60$ years & 1859 & $13(0.7 \%)$ & 3879 & $15(0.38 \%)$ & 0.154 & $1.814(0.861,3.20)$ \\
\hline Male aged $\geq 60$ years & 656 & $5(0.76)$ & 830 & $5(0.6 \%)$ & 0.757 & $1.267(0.365,4.396)$ \\
\hline Emergency admission & 2551 & $19(0.74 \%)$ & 3187 & $9(0.28 \%)$ & 0.020 & $2.650(1.197,5.867)$ \\
\hline Acute cholecystitis & 506 & $3(0.6 \%)$ & 5232 & $25(0.47 \%)$ & 0.733 & $1.242(0.374,4.129)$ \\
\hline Jaundice & 1043 & $14(1.3 \%)$ & 4695 & $14(0.29 \%)$ & $<0.001$ & $4.559(2.162,9.571)$ \\
\hline Previous cholecystitis & 328 & $6(1.8 \%)$ & 5410 & $22(0.4 \%)$ & 0.004 & $4.577(1.843,11.367)$ \\
\hline Previous jaundice & 304 & $2(0.65 \%)$ & 5434 & $26(0.48 \%)$ & 0.659 & $1.377(0.325,5.831)$ \\
\hline USS thick or contracted GB & 872 & $7(0.8 \%)$ & 4866 & $21(0.43 \%)$ & 0.180 & $1.867(0.791,4.405)$ \\
\hline USS Dilated CBD & 937 & $12(1.28 \%)$ & 4801 & $16(0.33 \%)$ & 0.001 & $3.880(1.829,8.228)$ \\
\hline Previous abdominal surgery & 1759 & $5(0.28 \%)$ & 3979 & $23(0.57 \%)$ & 0.156 & $0.490(0.186,1.292)$ \\
\hline Risk factors for CBD stones & 2047 & $19(0.93 \%)$ & 3691 & $9(0.24 \%)$ & 0.001 & $3.833(1.731,8.487)$ \\
\hline
\end{tabular}

Table 2 Causes of open conversion

\begin{tabular}{ll}
\hline Main reason for conversion & Number of patients \\
\hline Impacted CBD stones (Non Mirizzi) & $7(25 \%)$ \\
Adhesions GB to omentum, hepatic flexure, duodenum & $7(25 \%)$ \\
Adhesions. Distant. Bowel injury & $2(7 \%)$ \\
Mirizzi ( includes 1 with impacted CBD stone) & $4(14 \%)$ \\
Failure to establish pneumoperitoneum & $2(7 \%)$ \\
Bleeding, liver cirrhosis & $1(3.5 \%)$ \\
Suspicion of malignancy & $1(3.5 \%)$ \\
Cholecystoduodenal fistula & $1(3.5 \%)$ \\
Unclear anatomy & $1(3.5 \%)$ \\
Slipped T tube after LCBDE & $1(3.5 \%)$ \\
CBD stricture (cholangiocarcinoma) & $1(3.5 \%)$ \\
\hline
\end{tabular}

cholecystectomies performed over the last 20 years were completed laparoscopically.

The median duration of surgery was $195 \min (70-420)$. The median duration for the whole series was $71 \mathrm{~min}$ for LC and 119 min in the 1318 patients who underwent CBD exploration.

The total hospital stay ranged from 4 to 95 days with a median of 11 days. 16 converted patients had bile duct exploration earlier in the series. Their longer hospital stay (median 14 days, range 7-30) reflected the need for biliary drains in 11 patients, bilioenteric anastomosis in 6 and 6 having had postoperative complications including retained stones requiring ERCP in 3 patients. The median number of admission episodes was 1 ; only 6 patients had two admissions and 3 had three, including all previous admissions and re-admissions. The presentation to resolution period ranged from 1 to 30 weeks with a median of 2 .

Morbidity within this group of patients was relatively high with a complication rate of $32 \%$. The different complications encountered, their management and outcome are summarised in Table 3. There were no deaths.
During the period of this study, no patients were preselected for open cholecystectomy on account of expected difficulty, e.g. previous abdominal surgery or confirmed bile duct stones. Three patients had cholecystectomies during two open gastrectomies and one splenectomy. However, four patients were referred to a liver surgery unit for biliary reconstruction immediately after $L C$; two with bile duct injuries and two with Mirizzi Type III and IV. All underwent open surgery within $24 \mathrm{~h}$ of the original laparoscopic procedures.

\section{Discussion}

The incidence of open conversion in the literature is subject to wide variations in the clinical presentations, experience of the surgeons and the gallbladder pathology they encountered. The conversion rate in our series was just under $0.5 \%$ in spite of a $44 \%$ incidence of emergency admissions and a high rate (23\%) of laparoscopic CBD explorations (LCBDE). Subgroup analysis of 12 conversions in our 4426 
Table 3 Complications encountered in the conversion patients in our series and their management

\begin{tabular}{|c|c|c|c|c|c|}
\hline Complication & Number & Readmission & Re-intervention & $\begin{array}{l}\text { Clavien-Dindo } \\
\text { classification }\end{array}$ & Hospital stay/days \\
\hline Retained stones & $3(10.7 \%)$ & 1 & 3 ERCP & G IIIa & $24,14,10$ \\
\hline Abdominal collections & $2(7 \%)$ & 1 & $\begin{array}{l}1 \mathrm{P} / \mathrm{C} \text { Drain } \\
1 \text { conservative }\end{array}$ & $\begin{array}{l}\text { G IIIa } \\
\text { G II }\end{array}$ & $\begin{array}{l}30 \\
21\end{array}$ \\
\hline Bile leak & $1(3.5 \%)$ & & Conservative & G I & 12 \\
\hline Intestinal fistula/abdominal collection & $1(3.5 \%)$ & 1 & $\mathrm{P} / \mathrm{C}$ drain, settled & G IIIa & 95 \\
\hline Chest infection & $1(3.5 \%)$ & & Conservative & G II & 7 \\
\hline Bile leak due to cholangiocarcinoma & $1(3.5 \%)$ & & ERCP & G IIIa & 21 \\
\hline
\end{tabular}

patients undergoing LC without LCBDE, reflecting the current practice of staged management of bile duct stones, would result in an adjusted conversion rate of $0.27 \%$.

The CholeS study was a large prospective study assessing outcomes and variations in practice of cholecystectomy performed across the United Kingdom in 8820 patients in March and April 2014 [14]. The conversion rate of 3.4\% may therefore reflect current practice and the different causes of conversion in the United Kingdom.

\section{Predictors of conversion}

Various preoperative and operative risk factors for open conversions have been suggested. The CLOC score (Conversion from Laparoscopic to Open Cholecystectomy) derived from the CholeS study database identified older age, American Society of Anaesthesiologists (ASA) classification, male gender, indication for surgery, CBD diameter and gallbladder wall thickness as significant independent predictors of conversion on multivariate analysis [15]. The type of admission and preoperative ERCP were predictive of conversion on univariate analysis but not on multivariate analysis. Although our 152 patients with preoperative ERCP had higher grades of operative difficulty, none were in the conversion group. The Body Mass Index (BMI) was not a risk factor for conversion in either study.

The indication for surgery scoring highest in the CLOC score was the presence of CBD stones. This mirrors the results of our series. The conversion rate for those presenting with jaundice was $1.3 \%$, compared to $0.29 \%$ for nonjaundiced patients: $p<0.001$. However, while $57 \%$ of our converted patients underwent CBD explorations, there were only $12 \%$ in the CholeS study. It was not clear whether, at least in some cases, this was the result of the need to convert to deal with unexpected bile duct stones or of difficulties encountered during planned laparoscopic CBD explorations necessitating conversion. CholeS reported a total of 557 patients with bile duct stones (6.3\%) versus $1318(23 \%)$ in this series. The preoperative characteristics predictive of conversion in this study vs. the national study are summarised in Table 4.

Overall morbidity of the converted patients in the CholeS study $(33 \%)$ was similar to ours. However, while the operative difficulty grading was comparable, our median operative
Table 4 Preoperative characteristics predictive of conversion in our series vs. CholeS study

\begin{tabular}{lllll}
\hline & This study & CholeS & $p$ value & OR (95\% CI) \\
\hline Conversions & $28 / 5738(0.49 \%)$ & $221 / 6615(3.34 \%)^{*}$ & 0.00001 & $0.142(0.096-0.211)$ \\
Age $\geq 50$ years & $17(60.7 \%)$ & $179(81 \%)$ & 0.025 & $0.363(0.158-0.831)$ \\
Male gender & $10(35.7 \%)$ & $111(50 \%)$ & 0.165 & $0.551(0.243-1.246)$ \\
Emergency admission & $18(64.3 \%)$ & $57(26 \%)$ & 0.0001 & $5.179(2.259-11.873)$ \\
Preoperative ERCP & $0 \%$ & $57(26 \%)$ & 0.001 & Not applicable \\
Main indication for surgery & & & & \\
$\begin{array}{l}\text { Acute Cholecystitis } \\
\text { Pancreatitis }\end{array}$ & $3(10.7 \%)$ & $123(56 \%)$ & 0.001 & $0.096(0.028-0.326)$ \\
$\begin{array}{l}\text { CBD stone/jaundice } \\
\text { Thick-walled gall bladder on } \\
\quad \text { ultrasound }\end{array}$ & $7(25 \%)$ & $13(6 \%)$ & 0.3714 & Not applicable \\
Dilated CBD on ultrasound & $11(39.3 \%)$ & $66(30 \%)$ & 0.002 & $3.922(1.731-8.885)$ \\
\hline
\end{tabular}

*CholeS data were divided into two random groups with similar conversion rates: one to produce a risk score and one to validate the resulting score 
time and hospital stay were longer than in the CholeS study for the converted patients (Table 5). This is likely due to the high incidence of bile duct exploration in our study as our "LC only" conversions have a median operative time of 130 min and a hospital stay of 8 days, both similar to CholeS.

Shamieh et al. [16] reported a conversion rate of $5.4 \%$ in 5048 patients, with acute cholecystitis accounting for $29 \%$ of conversions followed by unclear Calot's triangle anatomy in $17 \%$ and dense adhesions in $14 \%$. CBD exploration accounted for only $3.7 \%$ of conversions in that institution where laparoscopic ductal exploration was not available. In addition, $11 \%$ were preselected for open cholecystectomy without a laparoscopic attempt.

Tuveri et al. [17] reported a $3.6 \%$ conversion in 1965 patients. Acute cholecystitis of a duration $>72 \mathrm{~h}, \mathrm{BMI}$ of over 30 and patients with previous gastric surgery were excluded. FFD was the main focus of the study with 29 attempted and 6 converted. 6 patients had CBD stones, 4 dealt with laparoscopically and 2 converted. It was not clear how CBD stones in the non-FFD group were dealt with. The reasons for conversion were Mirizzi syndrome, Cholecystoduodenal fistula, dense adhesions and short, wide cystic duct.

\section{Conversion in laparoscopic bile duct exploration}

A meta-analysis of 13 studies including 872 LCBDE [18] reported a conversion rate of $4.1 \%$. No details of the exact causes of conversion were given. Another meta-analysis [19] comparing transcystic and transductal CBD exploration in 26 studies including 3396 patients reported conversion rates of $3.2 \%$ and $2.4 \%$ for these exploration modalities, respectively, with no details of the causes of conversion.
Our overall conversion rate was $1.2 \%$ : $3 / 871(0.34 \%)$ for transcystic and 13/447 (2.9\%) for transductal exploration.

Paganini et al. [20] reported 344 LCBDE with a conversion rate of $4.4 \%$, the cause of conversion being dense adhesions in 33\% and impacted stones in 20\%. Our series of 1318 LCBDE with 16 conversions had impacted CBD stones in 6 (37\%), adhesions in 4 (25\%), need for hepaticojejunostomy in $3(19 \%)$ and miscellaneous causes in 3 . Once beyond the learning curve, there were only four conversions in the last 1243 ductal explorations, a conversion rate of $0.32 \%$ not dissimilar to that for $\mathrm{LC}$ alone. The learning curve for bile duct exploration was also reported by Paganini et al. as the reason for 3 of their 15 conversions.

Conversion rates improve with growing experience and case volume (Fig. 3). Most conversions occurred in the first 7 years. Specialising in biliary emergencies, routine cholangiography, refining the techniques for difficult laparoscopic bile duct explorations and a trend towards using FFD in difficult LC reduced conversions to 8 of the last 5198 cases $(0.15 \%)$ over 22 years.

\section{Salvage strategies}

173 patients underwent laparoscopic FFD (6 converted) and 6 had laparoscopic SC, $85 \%$ graded IV-V on the Nassar difficulty scale. FFD was performed when the cystic duct pedicle was encased in dense adhesions, when the cystic artery and duct could not be separated, when Hartmann's pouch was found to be densely adherent to the common bile duct, and when the presence of a Mirizzi abnormality was suspected. We have previously described the technique of FFD and its effect on the conversion rate [21].

Subtotal cholecystectomy and FFD were proposed as important strategies in dealing with difficult LC in several studies reporting different outcomes [22-25]. The
Table 5 Operative parameters and postoperative outcomes of conversions

\begin{tabular}{lllll}
\hline & This study no=5738 & CholeS no=8820 & $p$ value & OR (95\% CI) \\
\hline $\begin{array}{l}\text { No of conversions } \\
\text { Nassar difficulty grade }\end{array}$ & $28(0.49 \%)$ & $297(3.37 \%)$ & 0.00001 & $0.146(0.099-0.215)$ \\
IV + V & $20(71.4 \%)$ & $212(71.4 \%)$ & 1 & $1.002(0.425-2.363)$ \\
III & $4(14.2 \%)$ & $65(21.8 \%)$ & 0.4708 & $0.595(0.199-1.776)$ \\
II & $2(7.1 \%)$ & $12(4 \%)$ & 1 & $1.827(0.388-8.606$ \\
I & $2(7.1 \%)$ & $7(2.3 \%)$ & 0.1674 & $3.187(0.629-16.134$ \\
Median operative time & $195 \mathrm{~min}$ & $120 \mathrm{~min}$ & & \\
Median Hospital stay & 11 days & 6 days & & \\
Mortality & $0 \%$ & $2(0.7 \%)$ & 1 & Not applicable \\
Total morbidity & $9(32 \%)$ & $98(33 \%)$ & 0.8321 & $0.962(0.420-2.204)$ \\
Bile leak & $1(3.5 \%)$ & $25(8 \%)$ & 0.7096 & $0.403(0.053-3.091)$ \\
Bile duct injury & $0 \%$ & $6(2 \%)$ & 1 & Not applicable \\
\hline
\end{tabular}

${ }^{a}$ Two bile duct injuries occurred in this series but were not converted. They underwent open biliary reconstruction at a liver surgery unit within $24 \mathrm{~h}$. Satisfactory symptom-free follow-up of 8 and 15 years 
Table 6 Comparison of the outcomes of fundus first dissection \& subtotal cholecystectomy

\begin{tabular}{|c|c|c|c|c|c|c|c|c|}
\hline & $\begin{array}{l}\text { No of LC } \\
\text { cases in series }\end{array}$ & $\begin{array}{l}\text { Incidence of } \\
\text { FFD/SC }\end{array}$ & $\begin{array}{l}\text { Total conversion } \\
\text { rate }\end{array}$ & $\begin{array}{l}\text { Potential } \\
\text { conversion } \\
\text { without FF/ } \\
\text { SC }\end{array}$ & $\begin{array}{l}\text { IOC with } \\
\text { FFD/SC }\end{array}$ & $\begin{array}{l}\text { Overall } \\
\text { complication } \\
\text { rate with FFD/ } \\
\mathrm{SC}(\%)\end{array}$ & $\begin{array}{l}\text { Residual CBD } \\
\text { stones after } \\
\text { FFD/SC }(\%)\end{array}$ & $\begin{array}{l}\text { Lap CBD } \\
\text { explora- } \\
\text { tion }\end{array}$ \\
\hline $\begin{array}{l}\text { Nassar et al. } \\
\text { This study }\end{array}$ & 5738 & $2.8 \% / 0.08 \%$ & $\begin{array}{l}0.49 \%(+3 \text { open } \\
\text { from start- } \\
0.052 \%)\end{array}$ & $3.5 \%$ & $93.8 \%$ & 12.6 & 1.2 & Yes \\
\hline $\begin{array}{l}\text { Hubert et al. } \\
\text { [23] }\end{array}$ & $\begin{array}{l}500 \text { (elective } \\
\text { only) }\end{array}$ & $7.1 \%$ & $\begin{array}{l}2 \%(+52 \text { open } \\
\text { from star-9\%) }\end{array}$ & $25.6 \%$ & $79.5 \%$ & 15.4 & 5.1 & No \\
\hline $\begin{array}{l}\text { ElShaer et al. } \\
\text { [25] }\end{array}$ & 1231 & $\begin{array}{l}100 \% \text { subtotal } \\
\text { (meta-anal- } \\
\text { ysis) }\end{array}$ & $\begin{array}{l}8 \% \text { ( }+19 \% \text { open } \\
\text { from start) }\end{array}$ & $8 \%$ & $4 / 30$ studies & 27 & 3 & No \\
\hline $\begin{array}{l}\text { Sormaz et al. } \\
\text { [7] }\end{array}$ & 213 & $6.2 \% / 2.8 \%$ & $\begin{array}{l}1.4 \%(+27 \text { open } \\
\text { from start } \\
\text { excluded-11\%) }\end{array}$ & $\begin{array}{l}0 \% \text { but } 46 \% \\
\text { of FFD } \\
\text { had SC }\end{array}$ & no & 15 & 7.5 & No \\
\hline $\begin{array}{l}\text { Gupta et al. } \\
{[24]^{\mathrm{a}}} \\
\text { (FFD only not } \\
\text { SC) }\end{array}$ & 145 & $\begin{array}{l}18.6 \% \text { in dif- } \\
\text { ficult LC }\end{array}$ & $\begin{array}{l}2 \% \text { (excluded fistu- } \\
\text { las, CBD stones, } \\
\text { cancer) }\end{array}$ & $4.1 \%$ & no & 1.5 & 0 & No \\
\hline $\begin{array}{l}\text { Tuveri et al. } \\
\text { [17] }\end{array}$ & $\begin{array}{l}1965 \\
(>72 \text { h AC* } \\
\text { excluded })\end{array}$ & $1.5 \%$ & $3.4 \%$ & $20 \%$ & $60 \%$ & 20 & 6.9 & Yes \\
\hline
\end{tabular}

${ }^{a}$ Gupta randomised $31 \%$ LC to FFD preoperatively regardless of difficulty and resorted to FFD due to difficulty in an additional $18.6 \%$ in the conventional LC group

fenestrating SC technique is preferred by most authors [26]. However, the, risks of bile leakage and of stones left in the gallbladder remnant are a cause for concern, whether the fenestrating or the reconstituting method is used. In this series, we rarely resorted to subtotal cholecystectomy, excising as much of the gallbladder as possible, ensuring the removal of all stones from the cystic duct stump and performing cholangiography or choledochoscopy to avoid retained CBD stones. Table 6 compares the outcomes of our series and some studies with similar characteristics in relation to the effect of FFD and SC on the conversion rates. However, unlike in our series, some authors have preselected patients for open cholecystectomy excluding cases from LC on the grounds of expected difficulty or due to the presence of bile duct stones.

Although CBD stones caused most conversions in this series, only two conversions were needed in the last 1150 to perform biliary enteric anastomosis for a Mirizzi Type 2 and an impacted stone at the ampulla. Stone fragmentation using biopsy forceps, ultrasound lithotripsy and laser lithotripsy facilitated laparoscopic completion of 118 cases with impacted CBD stones. The utilisation of choledoscopy is essential in all cases.

Mirizzi syndrome caused 4 conversions in this cohort, 3 Type I and 1 Type II [13]. CBD stones encountered in a Type III and a Type IV were dealt with laparoscopically but the patients were subsequently referred to liver surgery units for biliary reconstruction. Subspecialisation helped to achieve definitive one-session laparoscopic treatment in $89 \%$ of the 58 Mirizzi Syndrome patients in our series.

\section{Conclusion}

Open conversion should not be regarded as a complication or a failure in laparoscopic cholecystectomy. It is occasionally the safest option for the patient when encountering a difficult gallbladder. Nevertheless, conversion still carries a high complication rate and it is good practice to consult a more experienced surgeon where available before resorting to conversion. FFD and SC are useful salvage techniques which are proven to reduce the conversion rate. Subspecialisation in managing biliary emergencies, with or without single stage management of bile duct stones, can reduce the conversion rates in difficult cholecystectomies and bile duct explorations.

\section{Compliance with ethical standards}

Disclosures Ahmad H. M. Nassar, Hisham El Zanati, Hwei J. Ng, Khurram S. Khan and Colin Wood have no conflicts of interest or financial ties to disclose.

Open Access This article is licensed under a Creative Commons Attribution 4.0 International License, which permits use, sharing, 
adaptation, distribution and reproduction in any medium or format, as long as you give appropriate credit to the original author(s) and the source, provide a link to the Creative Commons licence, and indicate if changes were made. The images or other third party material in this article are included in the article's Creative Commons licence, unless indicated otherwise in a credit line to the material. If material is not included in the article's Creative Commons licence and your intended use is not permitted by statutory regulation or exceeds the permitted use, you will need to obtain permission directly from the copyright holder. To view a copy of this licence, visit http://creativecommons .org/licenses/by/4.0/.

\section{References}

1. Coelho JCU, Dalledone GO, Schiel W, Berbardin JP, Claus CMP, Marias JEF, Freitas ACT (2019) Does male gender increase the risk of laparoscopic cholecystectomy? ABCD Arq Bras Cir Dig 32(2):e1438

2. Kaafarani HM, Smith TS, Neumayer L, Berger DH, Depalma RG, Itani KM (2010) Trends, outcomes, and predictors of open and conversion to open cholecystectomy in Veterans Health Administration hospitals. Am J Surg 200(1):32-40

3. Gholipour C, Fakhree MBA, Shalchi RA, Abbasi M (2009) Prediction of conversion of laparoscopic cholecystectomy to open surgery with artificial neural networks. BMC Surg 9(1):13

4. Tang B, Cuschieri A (2006) Conversions during laparoscopic cholecystectomy: risk factors and effects on patient outcome. J Gastrointest Surg 10(7):1081-1091

5. Peters JH, Krailadsiri W, Incarbone R et al (1994) Reasons for conversion from laparoscopic to open cholecystectomy in an urban teaching hospital. Am J Surg 168(6):555-559

6. Lengyel BI, Panizales MT, Steinberg J, Ashley SW, Tavakkoli A (2012) Laparoscopic cholecystectomy: what is the price of conversion? Surgery 152(2):173-178

7. Sormaz İC, Soytaş Y, Gök AFK, Özgür İ, Avtan L (2018) Fundus-first technique and partial cholecystectomy for difficult laparoscopic cholecystectomies. Ulus Travma Acil Cerrahi Derg 24:66-70

8. Flowers JL, Bailey RW, Scovill WA, Zucker KA (1991) The Baltimore experience with laparoscopic management of acute cholecystitis. Am J Surg 161:388-392

9. Guidelines for the Clinical Application of Laparoscopic Biliary Tract Surgery (2016) SAGES. http://www.sages.org/publications/ guidelines/guidelines-for-the-clinical-application-of-laparoscop ic-biliary-tract-surgery. Accessed 20 June 2020

10. Griffiths EA, Hodson J, Vohra RS, Marriott P, Katbeh T, Zino S, Nassar AHM (2019) Utilisation of an operative difficulty grading scale for laparoscopic cholecystectomy. Surg Endosc 33(1):110-121

11. Nassar AHM, Shallaly GE, Hamouda A (2009) Optimising laparoscopic cholangiography time using a simple cannulation technique. Surg Endosc 23(3):513-517

12. El ZH, Nassar AHM, Zino S, Katbeh T, Ng HJ, Abdellatif A (2020) Gall bladder empyema: early cholecystectomy during the index admission improves outcomes. JSLS 24(2):e2020

13. Nassar AHM, Nassar MK, Gil IC et al (2020) One-session laparoscopic management of Mirizzi syndrome: feasible and safe in specialist units. Surg Endosc. https://doi.org/10.1007/s00464-02007765-4

14. CholeS Study Group, West Midlands Research Collaborative (2016) Population-based cohort study of outcomes following cholecystectomy for benign gallbladder diseases. Br J Surg 103(12):1704-1715. https://doi.org/10.1002/bjs.10287

15. Sutcliffe RP, Hollyman M, Hodson J et al (2016) Preoperative risk factors for conversion from laparoscopic to open cholecystectomy: a validated risk score derived from a prospective U.K. database of 8820 patients. HPB (Oxford) 18(11):922-928. https ://doi.org/10.1016/j.hpb.2016.07.015

16. Shamiyeh A, Danis J, Wayand W, Zehetner J (2007) A 14-year analysis of laparoscopic cholecystectomy: conversion-when and why? Surg Laparosc Endosc Percutaneous Tech 17(4):271-276. https://doi.org/10.1097/SLE.0b013e31805d093b

17. Tuveri M, Calò PG, Medas F, Tuveri A, Nicolosi A (2008) Limits and advantages of fundus-first laparoscopic cholecystectomy: lessons learned. J Laparoendosc Adv Surg Tech A 18(1):69-75. https ://doi.org/10.1089/lap.2006.0194

18. Pan L, Chen M, Ji L et al (2018) The safety and efficacy of laparoscopic common bile duct exploration combined with cholecystectomy for the management of cholecysto-choledocholithiasis: an up-to-date meta-analysis. Ann Surg 268(2):247-253

19. Hajibandeh S, Hajibandeh S, Sarma DR et al (2019) Laparoscopic transcystic versus transductal common bile duct exploration: a systematic review and meta-analysis. World J Surg 43:1935-1948

20. Paganini AM, Guerrieri M, Sarnari J et al (2005) Long-term results after laparoscopic transverse choledochotomy for common bile duct stones. Surg Endosc 19:705-709

21. Mahmud S, Masaud M, Canna K, Nassar AHM (2002) Fundusfirst laparoscopic cholecystectomy A safe means of reducing the conversion rate. Surg Endosc 16:581-584

22. Sormaz IC, Soytaş Y, Gök AFK, Özgür I, Avtan L (2018) Fundus-first technique and partial cholecystectomy for difficult laparoscopic cholecystectomies. Ulus Travma Acil Cerrahi Derg 24(1):66-70

23. Hubert C, Annet L, van Beers BE, Gigot JF (2010) The "inside approach of the gallbladder" is an alternative to the classic Calot's triangle dissection for a safe operation in severe cholecystitis. Surg Endosc 24(10):2626-2632. https://doi.org/10.1007/s0046 4-010-0966-5

24. Gupta A, Agarwal PN, Kant R, Malik V (2004) Evaluation of fundus-first laparoscopic cholecystectomy. JSLS 8(3):255-258

25. Elshaer M, Gravante G, Thomas K, Sorge R, Al-Hamali S, Ebdewi H (2015) Subtotal cholecystectomy for "difficultgallbladders" systematic review and meta-analysis. JAMA Surg 150(2):159-168

26. Lecompte MT, Robbins KJ, Williams GA et al (2020) Less is more in the difficult gallbladder: recent evolution of subtotal cholecystectomy in a single HPB unit. Surg Endosc. https://doi. org/10.1007/s00464-020-07759-2

Publisher's Note Springer Nature remains neutral with regard to jurisdictional claims in published maps and institutional affiliations. 